Check for updates

Cite this: J. Mater. Chem. C, 2019, 7, 12532

Received 5th August 2019,

Accepted 17th September 2019

DOI: $10.1039 / c 9 t c 04282 b$

rsc.li/materials-c

\section{Plasma-assisted atomic layer deposition of nickel oxide as hole transport layer for hybrid perovskite solar cells $\dagger$}

\author{
Dibyashree Koushik, (D)*a Marko Jošt, (D) ${ }^{\mathrm{b}}$ Algirdas Dučinskas, ${ }^{a}$ Claire Burgess, ${ }^{a}$ \\ Valerio Zardetto, ${ }^{C}$ Christ Weijtens, ${ }^{\text {a }}$ Marcel A. Verheijen, ${ }^{\text {ad }}$ \\ Wilhelmus M. M. Kessels, (D) ${ }^{\text {ac }}$ Steve Albrecht ${ }^{\text {be }}$ and Mariadriana Creatore (D) *ac
}

\begin{abstract}
Low-temperature atomic layer deposition (ALD) offers significant merits in terms of processing uniform, conformal and pinhole-free thin films, with sub-nanometer thickness control. In this work, plasma-assisted atomic layer deposition (ALD) of nickel oxide (NiO) is carried out by adopting bis-methylcyclopentadienylnickel $\left(\mathrm{Ni}(\mathrm{MeCp})_{2}\right)$ as precursor and $\mathrm{O}_{2}$ plasma as co-reactant, over a wide table temperature range of $50-300{ }^{\circ} \mathrm{C}$. A growth rate of $0.32 \AA$ per cycle is obtained for films deposited at $150{ }^{\circ} \mathrm{C}$ with an excellent thickness uniformity on a 4 inch silicon wafer. Bulk characteristics of the $\mathrm{NiO}$ film together with its interfacial properties with a triple cation hybrid perovskite absorber layer are comprehensively investigated, with the aim of integrating $\mathrm{NiO}$ as hole transport layer $(\mathrm{HTL})$ in a $\mathrm{p}-\mathrm{i}-\mathrm{n}$ perovskite solar cell (PSC) architecture. It is concluded that "key" to efficient solar cell performance is the post-annealing treatment of the ALD NiO films in air, prior to perovskite synthesis. Post-annealing leads to better wettability of the perovskite layer and increased conductivity and mobility of the $\mathrm{NiO}$ films, delivering an increase in short-circuit current density $\left(J_{\mathrm{sc}}\right)$ and fill factor (FF) in the fabricated devices. Overall, a superior 17.07\% PCE is achieved in the post-annealed $\mathrm{NiO}$-based PSC when compared to the 13.98\% PCE derived from the one with pristine NiO.
\end{abstract}

\section{Introduction}

The bloom of hybrid organic-inorganic perovskite solar cells (PSCs) with outstanding power conversion efficiencies (PCEs) ${ }^{1}$ has captured great interest in the photovoltaic (PV) community. Over the last years, novel interfacial designing approaches and efficient charge transport layers (CTLS) have been introduced to foster the advancement of this PV technology. It has been demonstrated that the quality of the perovskite/CTL interface

\footnotetext{
${ }^{a}$ Department of Applied Physics, Eindhoven University of Technology, 5600 MB Eindhoven, The Netherlands.E-mail: d.koushik@tue.nl, M.Creatore@tue.nl

${ }^{b}$ Young Investigator Group Perovskite Tandem Solar Cells, Helmholtz-Zentrum Berlin für Materialien und Energie GmbH, Kekuléstraße 5, 12489 Berlin, Germany

${ }^{c}$ Solliance Solar Research, High Tech Campus 21, 5656 AE Eindhoven, The Netherlands

${ }^{d}$ Eurofins Materials Science BV, High Tech Campus 11, 5656 AE Eindhoven, The Netherlands

${ }^{e}$ Technical University Berlin, Faculty IV-Electrical Engineering and Computer Science, 10587 Berlin, Germany

$\dagger$ Electronic supplementary information (ESI) available: Details on UPS data analysis, cross-sectional TEM image of PSC with post-annealed ALD NiO, comparative EQE spectra and box-plot of the PV parameters of pristine and post-annealed NiO-based PSCs, TEM-EDX elemental mappings of $\mathrm{I}, \mathrm{Br}, \mathrm{Pb}, \mathrm{In}, \mathrm{O}$ and $\mathrm{Cu}$ present in the perovskite device stack, AR-XPS spectra of $\mathrm{Ni} 2 \mathrm{p}_{3 / 2}$ and $\mathrm{O} 1 \mathrm{~s}$ of the pristine NiO film measured with $\theta$ of $90^{\circ}$ and $15^{\circ}$, UPS spectra of the employed triple cation-based perovskite layer, transmittance spectra of the pristine and post-annealed ALD NiO films. See DOI: 10.1039/c9tc04282b
}

plays a vital role in determining how efficiently the charges can be extracted, influencing the overall operation of the fabricated solar cells. ${ }^{2,3}$

Recently, the inverted PSC (p-i-n) configuration has received tremendous attention owing to its advantages over the conventional n-i-p configuration, such as simple, low-processing temperature, ${ }^{4}$ negligible hysteresis effect, ${ }^{4,5}$ and its potential in tandem solar cells. ${ }^{6-8}$ Replacing the conventional organic hole transport layers (HTLs) with inorganic alternatives contributes to improve device robustness, reduce parasitic absorption losses and tackle scalable processing challenges. ${ }^{9,10}$ In case of $\mathrm{p}-\mathrm{i}-\mathrm{n}$ perovskite-based tandems, solution-based deposition of organic HTL (spiro-TTB) on randompyramid textured Si solar cells was recently demonstrated to result in poor surface coverage, leading to recombination centers and potential shunting in the devices. ${ }^{11} \mathrm{~A}$ similar effect can be expected when processing organic HTLs on CIGSe solar cells, which have a typical surface root-mean-square roughness in the range of $50-200 \mathrm{~nm}$, with lateral feature sizes typically in the order of $500 \mathrm{~nm}$ to $1 \mu \mathrm{m} .^{12}$

Nickel oxide (NiO) as inorganic HTL is a potential candidate, ${ }^{13}$ as it can chemically withstand most of the solvents used in PSCs. In addition, it does not corrode the underlying ITO substrate, in contrast to the commonly employed poly(3,4-ethylenedioxythiophene)-poly(styrenesulfonate) (PEDOT:PSS) HTL. It has a wide 
direct band gap (3.4-3.8 eV) which allows for high optical transmittance. In addition, a deep valence band edge $(\sim 5.4 \mathrm{eV})$ results in a good energy band alignment with several perovskite compositions, delivering high open circuit voltages $\left(V_{\text {oc }}\right)$ in the fabricated solar cells. ${ }^{9}$ To date, several reports have demonstrated PSCs with NiO fabricated by low-temperature solution-processes and vacuum-based deposition techniques. ${ }^{9}$ However, NiO films deposited by low-temperature solution processing usually contain defects and uncontrolled incorporation of impurities which affect light transmission and carrier transport properties. ${ }^{14}$ When adopting vacuum-based deposition techniques, such as sputtering and pulsed-laser deposition, NiO films as thick as $15-50 \mathrm{~nm}$ are implemented in the device, in order to prevent any potential shunting pathways. This approach, however, eventually leads to undesirable parasitic absorption losses in the cells. ${ }^{15-18}$ This motivates the present study and the adoption of deposition techniques that can guarantee the preparation of ultrathin, pinhole-free, low-temperature processed NiO films with excellent conformality that can be grown on both flat and textured surfaces.

From this perspective, atomic layer deposition (ALD) is the ideal deposition method. ${ }^{19,20}$ The application of ALD NiO films as HTL has notably contributed to achieve efficient performance in both perovskite-based single-junction and tandem solar cells. $^{21-23}$ Our very recent work showed the implementation of a conformal ALD NiO HTL on top of a rough CIGSe surface for obtaining a monolithic perovskite/CIGSe tandem device with 21.6\% PCE. It was highlighted that a $10 \mathrm{~nm}$ plasma-assisted ALD NiO layer processed directly on top of the ITO front contact of the rough CIGSe bottom cell helped in preventing any potential shunting in the fabricated tandem device. ${ }^{8}$ Seo et al. demonstrated the implementation of thermal ALD NiO films with thickness in the range of 6-7.5 $\mathrm{nm}$ in $\mathrm{CH}_{3} \mathrm{NH}_{3} \mathrm{PbI}_{3}$ and $\mathrm{Cs}_{0.05} \mathrm{MA}_{0.95} \mathrm{PbI}_{3}$-based p-i-n PSCs. ${ }^{2,23}$ PCE values of $16.4 \%$ and $17.22 \%$ were achieved for the $\mathrm{CH}_{3} \mathrm{NH}_{3} \mathrm{PbI}_{3}$ and $\mathrm{Cs}_{0.05}$ $\mathrm{MA}_{0.95} \mathrm{PbI}_{3}$-based devices, respectively. ${ }^{22,23}$
In order to stimulate the development of ALD processes for NiO, earlier studies employed Ni precursors such as, acetyl acetonate $\left(\mathrm{Ni}(\mathrm{acac})_{2}\right)$, nickel cyclopentadienyl $\left(\mathrm{Ni}(\mathrm{Cp})_{2}\right)$ and nickel ethylcyclopentadienyl $\left(\mathrm{Ni}(\mathrm{EtCP})_{2}\right)$. Owing to the low reactivity of these compounds toward water, ozone was typically used as co-reactant..$^{22,24-29}$ As alternatives, NiO processes with nickel bis(alkylamidinate) (Ni(AMD)), nickel(II) 1-dimethylamino-2-methyl-2-butoxide $\left(\mathrm{Ni}(\mathrm{dmamb})_{2}\right)$, nickel bis $\left(N, N^{\prime}\right.$-ditert-butylacetamidinate) $\left[\mathrm{Ni}\left({ }^{t} \mathrm{Bu}-\mathrm{MeAMD}\right)_{2}\right]$ and nickel 1-dimethylamino-2-methyl-2-propanolate $\left(\mathrm{Ni}(\mathrm{dmamp})_{2}\right)$ precursors were developed, which showed reactivity toward $\mathrm{H}_{2} \mathrm{O}$ at temperatures below $200{ }^{\circ} \mathrm{C}^{30-34}$ However, the cost of (Ni(AMD) $)_{2}$ ) precursor was shown to be higher than $\mathrm{Ni}(\mathrm{Cp})_{2},{ }^{35}$ and hence, developing ALD NiO processes with cost-effective, volatile Ni precursors together with a highly reactive oxidizing co-reactant (such as $\mathrm{O}_{2}$ plasma) started gaining attention. To this end, a couple of works demonstrated plasma-assisted $\mathrm{ALD}^{36}$ of $\mathrm{NiO}$ employing $\mathrm{Ni}(\mathrm{Cp})_{2}$ and $\left(\mathrm{Ni}(\mathrm{EtCp})_{2}\right)$ as precursors and $\mathrm{O}_{2}$ plasma as co-reactant, delivering growth per cycle (GPC) values of $0.037 \mathrm{~nm}\left(100-325{ }^{\circ} \mathrm{C}\right)$ and $0.042 \mathrm{~nm}\left(250{ }^{\circ} \mathrm{C}\right)$, respectively. ${ }^{35,37}$ To the best of our knowledge, there is only one plasma-assisted ALD process of $\mathrm{NiO}$ with bis-methylcyclopentadienyl-nickel $\left(\mathrm{Ni}(\mathrm{MeCp})_{2}\right)$ as precursor, however being demonstrated only on metallic substrates, such as $\mathrm{Pt}, \mathrm{Ru}$ and $\mathrm{W} .{ }^{38}$ The ALD temperature window was defined between 150 and $250{ }^{\circ} \mathrm{C}$, and GPC values of 0.048 , 0.058 and $0.084 \mathrm{~nm}$ were obtained at $250{ }^{\circ} \mathrm{C}$ on top of $\mathrm{Pt}, \mathrm{Ru}$ and $\mathrm{W}$, respectively. An overview of the ALD processes of $\mathrm{NiO}$ is presented in Table $1 .^{22,24,26,27,29,30,32-35,37-42}$

In this work, we develop a plasma-assisted ALD process of $\mathrm{NiO}$ employing $\mathrm{Ni}(\mathrm{MeCp})_{2}$ as precursor and $\mathrm{O}_{2}$ plasma as co-reactant within a temperature range of $50-300{ }^{\circ} \mathrm{C}$. The implementation of ultrathin $(10 \mathrm{~nm})$ conformal ALD NiO is then demonstrated in a triple cation-based $\mathrm{p}-\mathrm{i}-\mathrm{n}$ PSC. The bulk properties of the fabricated ALD NiO film together with its interfacial properties with the perovskite absorber layer are investigated comprehensively (ranging from structural, chemical

Table 1 Thermal and plasma-assisted ALD processes of NiO with different precursors and co-reactants

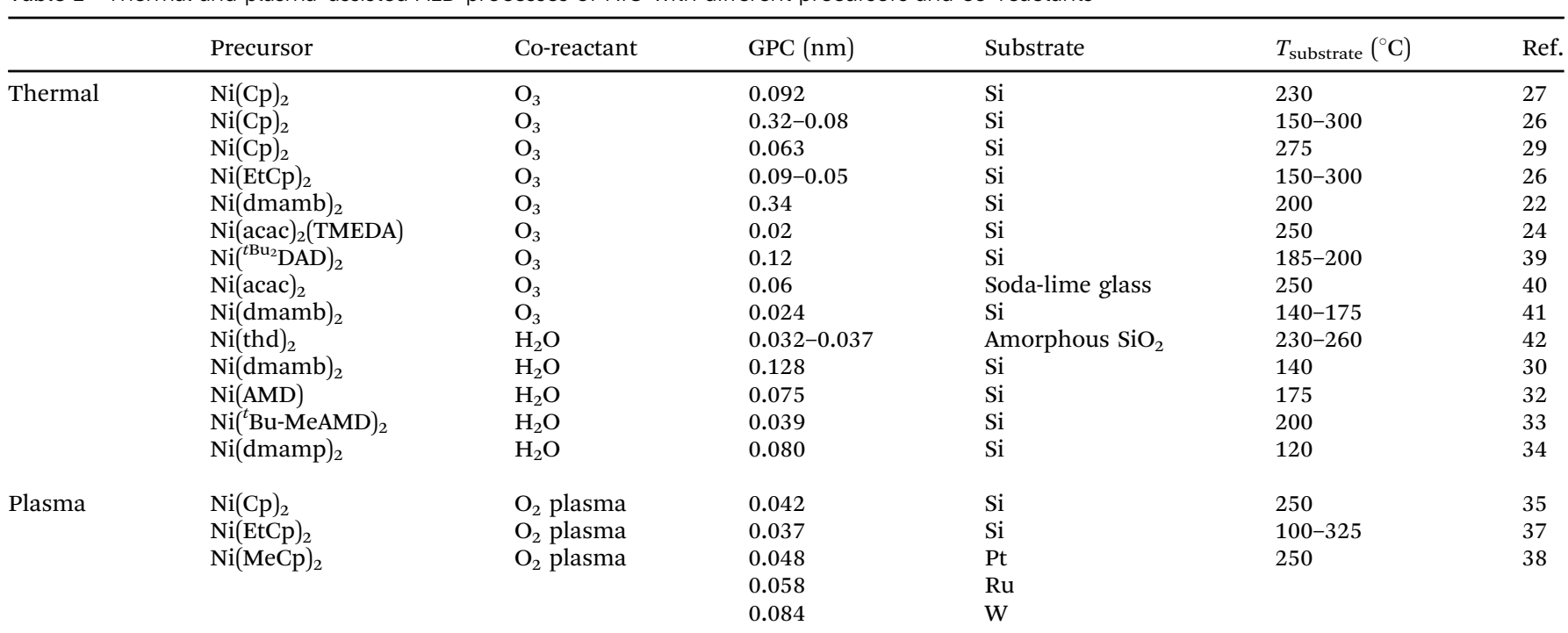


to opto-electrical properties), with the aim of identifying the key towards efficient implementation of NiO as HTL in PSCs. Improved interfacial and electrical properties are achieved by post-annealing the NiO films in air, resulting in an increase in PCE of the corresponding devices when compared to the ones fabricated with pristine $\mathrm{NiO}$.

\section{Experimental section}

\section{Atomic layer deposition (ALD) process of NiO}

$\mathrm{NiO}$ is deposited in a home-built ALD reactor, which is a highvacuum system coupled with a rotary and a turbo-molecular pump reaching a base pressure of $\sim 10^{-6} \mathrm{mbar}$. The system has been extensively described in our previous work. ${ }^{43}$ Prior to deposition, the reactor walls are pre-conditioned with 500 cycles of $\mathrm{ALD} \mathrm{Al}_{2} \mathrm{O}_{3}$. For the development of plasma-assisted ALD NiO process, all the depositions are performed on c-Si substrates having a thin native oxide layer $(\sim 1.5 \mathrm{~nm})$, unless mentioned otherwise. Depositions are performed at the table temperature range of $50-300{ }^{\circ} \mathrm{C}$. After an $\mathrm{O}_{2}$ plasma treatment $(100 \mathrm{~W})$ of $15 \mathrm{~min}$, ALD NiO is deposited using (Ni(MeCp) $)_{2}$ (97\%, SigmaAldrich) as precursor and $\mathrm{O}_{2}$ plasma as co-reactant. The $\mathrm{Ni}(\mathrm{MeCp})_{2}$ bubbler is kept at $55{ }^{\circ} \mathrm{C}$ to ensure adequate vapor pressure and is dosed using Ar carrier gas through a delivery line heated to $75{ }^{\circ} \mathrm{C}$. Each ALD cycle consists of $3 \mathrm{~s} \mathrm{Ni(MeCp})_{2}$ dose, $4 \mathrm{~s}$ purge time, $3 \mathrm{~S} \mathrm{O}_{2}$ plasma exposure $(100 \mathrm{~W})$ and $1 \mathrm{~s}$ purge time, as represented schematically in Fig. 1.

\section{Material characterization}

The thickness and optical properties of ALD NiO films deposited on c-Si substrates are determined by spectroscopic ellipsometry (SE) (NIR Ellipsometer M2000, J.A. Woollam Co.). The ellipsometric spectra are recorded after every ten ALD cycles over a wavelength range of $275-1600 \mathrm{~nm}$. Two Tauc-Lorentz oscillators are adopted to model the NiO films, as reported in the previous work by Lu et al. ${ }^{28}$ The thickness and optical constants of the NiO layer are obtained using the following fitting methodology. First, a Cauchy dispersion equation is utilized in the range of 450 to $1600 \mathrm{~nm}$ to extract the thickness, as NiO is transparent in this wavelength range. Using the obtained thickness value, the optical constants of the film are then determined over the entire recorded SE spectra (275-1600 $\mathrm{nm}$ ) using a B-spline model. A bandgap of $\sim 3.8 \mathrm{eV}^{21,28,35,44-46}$ is assumed for this fitting step

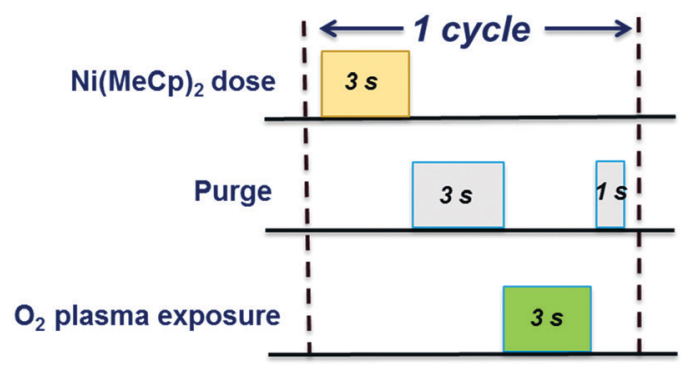

Fig. 1 Schematic of the standard recipe used for plasma-assisted ALD of $\mathrm{NiO}$. and an initial value of 2.1 is chosen for the refractive index (obtained from the Cauchy dispersion model at the largest wavelength of $1600 \mathrm{~nm}$ ). Thereafter, the optical constants are parameterized using two Tauc-Lorentz oscillators. ${ }^{28}$

The thickness uniformity is quantified by means of a Woollam ellipsometer M2000 and is determined by dividing the standard deviation $(\sigma)$ by the average mean NiO thickness.

The crystallinity of the ALD NiO samples is investigated by grazing incidence X-ray diffraction (GI-XRD) using a PANalytical X'Pert Pro MRD system, utilizing $\mathrm{Cu} K \alpha$ radiation $(\lambda=1.540598 \AA)$ in the $2 \theta$ range of $30^{\circ}$ to $80^{\circ}$ with a step size of $0.05^{\circ}$. XRD of the perovskite films are measured in Bragg-Brentano mode with a step size of $0.013^{\circ}$ in the range of $10^{\circ}$ to $50^{\circ}$.

Angle-resolved X-ray photoelectron spectroscopy (AR-XPS) is performed to investigate the chemical composition of the ALD NiO films using a Thermo Scientific KA1066 spectrometer. Monochromatic $\mathrm{Al} \mathrm{K} \alpha \mathrm{X}$-rays having an energy of $1486.6 \mathrm{eV}$ is utilized and the measurements are performed without any presputtering.

Contact angle is measured with Dataphysics OCA 15plus and analyzed with its software. Scanning electron microscopy (SEM) is performed with a Hitachi SEM. S-4100 at $5 \mathrm{kV}$ and $30000 \times$ magnification. Transmission electron microscopy (TEM) studies are performed using a JEOL ARM 200 probe corrected TEM operated at $200 \mathrm{kV}$. The system is equipped with a $100 \mathrm{~mm}^{2}$ Centurio SDD EDX detector. Cross-sectional TEM samples of the PSC are prepared using a standard Focused Ion Beam (FIB) lift-out procedure. Molybdenum support grids are used to mount the samples in the transfer step, upon which the final thinning is performed.

Ultraviolet photoelectron spectroscopy (UPS) measurements are performed in a multichamber VG EscaLab II system (Thermo Fisher Scientific Inc.) with a base pressure of $\sim 10^{-8} \mathrm{~Pa}$, using He-I radiation $(21.2 \mathrm{eV})$ generated in a differentially pumped discharge lamp while applying $-6 \mathrm{~V}$ bias to the sample.

Time-resolved photoluminescence (TRPL) measurements are performed using an in-house built system. A $635 \mathrm{~nm}$ pulsed laser operating at $5 \mathrm{MHz}$ is used, which incidents from the glass side of the perovskite/ALD NiO/ITO/glass samples.

For the electrochemical impedance spectroscopy (EIS) measurements, $10 \mathrm{~nm}$ films of ALD NiO deposited on fluorine doped tin oxide (FTO)/glass substrates are used as the working electrode, along with a $\mathrm{Ag} / \mathrm{AgCl}$ reference electrode and a platinum mesh counter electrode. ${ }^{22}$ The electrolyte solution is aqueous $1 \mathrm{M}$ $\mathrm{Na}_{2} \mathrm{SO}_{4}, 0.1 \mathrm{M}$ monobasic sodium phosphate, and is adjusted to pH 12 by dropwise addition of $\mathrm{NaOH}$ solution. The area of $\mathrm{NiO}$ in contact with the solution is $0.86 \mathrm{~cm}^{2}$. During the measurements, a sinusoidal $10 \mathrm{mV}$ perturbation of selected frequencies is applied at each bias voltage.

\section{Perovskite solar cell fabrication}

The fabricated PSCs have an inverted $(\mathrm{p}-\mathrm{i}-\mathrm{n})$ planar structure and a layer configuration of glass substrate/ITO/ALD NiO/ perovskite $\left(\mathrm{Cs}_{0.05}\left(\mathrm{MA}_{0.17} \mathrm{FA}_{0.83}\right) \mathrm{Pb}_{1.1}\left(\mathrm{I}_{0.83} \mathrm{Br}_{0.17}\right)_{3}\right) / \mathrm{C} 60 / \mathrm{BCP}$ (bathocuproine)/Cu. $10 \mathrm{~nm}$ ALD NiO layers are deposited on top of the ITO coated glass substrates. Thereafter, the NiO coated ITO 
substrates are annealed in air at $300{ }^{\circ} \mathrm{C}$ for $20 \mathrm{~min}$. All the perovskite layer deposition steps are carried out in $\mathrm{N}_{2}$ atmosphere. The perovskite layer is spin-coated using a one-step solution process (4000 rpm for $35 \mathrm{~s}$ ) following the triple cation procedure. $^{8} 25 \mathrm{~s}$ after the start of spinning, the ethyl acetate antisolvent drop $(400 \mu \mathrm{l})$ is utilized. The films are annealed at $100{ }^{\circ} \mathrm{C}$ for $1 \mathrm{~h}$. Afterwards, $23 \mathrm{~nm}$ C60 (Sigma Aldrich, purity $=99.9 \%$ ) is thermally evaporated at a rate of $0.15 \AA \mathrm{s}^{-1}$ at $400{ }^{\circ} \mathrm{C}$. The evaporation of $\mathrm{C} 60$ is followed by evaporation of $8 \mathrm{~nm}$ BCP. The cells are finished by evaporating $100 \mathrm{~nm} \mathrm{Cu}$ through a shadow mask. The final active area is $0.16 \mathrm{~cm}^{2}$.

\section{Perovskite solar cell characterization}

The current density-voltage $(J-V)$ measurements are performed under standard test conditions $\left(25^{\circ} \mathrm{C}\right.$, LED sun simulator, Wavelabs, class AAA), adjusted with a calibrated Si reference cell (Fraunhofer ISE). The scan rate is $0.25 \mathrm{~V} \mathrm{~s}^{-1}$ with a voltage step of $0.02 \mathrm{~V}$. The external quantum efficiency (EQE) is measured as a function of wavelength from 300 to $850 \mathrm{~nm}$ with a step of $10 \mathrm{~nm}$ using Oriel Instrument's QEPVSI-b system with $300 \mathrm{~W}$ xenon arc lamp, controlled by TracQ-Basic software.

\section{Results and discussion}

\section{ALD NiO film growth}

Fig. 2a-d show the saturation curves for the dose and purge steps of the $\mathrm{Ni}(\mathrm{MeCp})_{2}$ and $\mathrm{O}_{2}$ plasma. The self-limiting saturated growth behavior is confirmed for the ALD NiO process at a deposition temperature of $150{ }^{\circ} \mathrm{C}$. For the precursor saturation curve (Fig. 2a), the $\mathrm{O}_{2}$ plasma exposure time is fixed at $3 \mathrm{~s}$ while varying the precursor dosing time. For the $\mathrm{O}_{2}$ plasma saturation curve (Fig. 2c), the precursor dosing time is fixed at $3 \mathrm{~s}$ while varying the $\mathrm{O}_{2}$ plasma exposure. ALD saturating behavior is observed for both precursor and $\mathrm{O}_{2}$ plasma half-cycles at an exposure time of $3 \mathrm{~s}$. Meanwhile, negligible variation in GPC is observed with the precursor and $\mathrm{O}_{2}$ plasma purging times (Fig. 2b and d). Fig. 2e shows the thickness of NiO films as a function of number of ALD cycles, as-determined by in situ SE. As seen, the thickness increases linearly with the number of ALD cycles without experiencing any nucleation delay. The GPC in terms of thickness of the ALD NiO films for the investigated deposition temperatures of $50,100,150,200$, and $300{ }^{\circ} \mathrm{C}$ is shown in Fig. 2f. It is evident that the GPC decreases significantly from $\sim 0.44 \AA$ at $50{ }^{\circ} \mathrm{C}$ to $\sim 0.32 \AA$ at $150{ }^{\circ} \mathrm{C}$, and then stabilizes at $\sim 0.32 \AA$ for higher temperatures. The decrease in GPC with increasing deposition temperature could be due to reduction of $-\mathrm{OH}$ surface reactive groups due to thermally activated dehydroxylation reaction, and/or could result from densification of the material at higher deposition temperatures. ${ }^{47-51}$

Fig. 3 shows the thickness uniformity of the ALD NiO film on a 4 in $(100 \mathrm{~mm})$ c-Si wafer, evaluated by mapping its thickness over the whole wafer area by $\mathrm{SE}$ at room temperature. $700 \mathrm{ALD}$ cycles are performed at $150{ }^{\circ} \mathrm{C}$ on the c-Si wafer with a corresponding GPC of $\sim 0.32 \AA$. The thickness non-uniformity is deduced to be less than $0.16 \%$. A good thickness uniformity points out that the plasma-assisted ALD NiO process developed in this work could be utilized for growing these films on large area substrates.

\section{Structural and optical characterization of ALD NiO}

To characterize the degree of crystallinity of the as-deposited ALD NiO films, surface-sensitive GI-XRD measurement is performed, and the spectrum is shown in Fig. 4a. A face-centered cubic structure is demonstrated by the ALD NiO films as evidenced by the diffraction peaks located at $37.18^{\circ}, 43.23^{\circ}$, $62.92^{\circ}, 75.15^{\circ}$, which can be assigned to the (111), (200), (220) and (311) planes, respectively. The diffraction peaks ascribed to pure crystalline nickel, $\mathrm{Ni}(\mathrm{OH})_{2}$, and $\mathrm{Ni}_{2} \mathrm{O}_{3}$ phases are absent in the XRD spectrum of Fig. $4 a^{46,52}$ The XRD results are in agreement with the earlier reports for NiO films deposited via solution processes, ${ }^{52}$ sputtering, ${ }^{16}$ electron-beam-evaporation, ${ }^{46}$ and by ALD (for processes employing different precursor and co-reactant). ${ }^{22,35}$

The refractive index $(n)$ and extinction coefficient $(k)$ values of $23 \mathrm{~nm}$ pristine ALD NiO films extracted from SE are presented in Fig. 4b. The energy dependence of $\mathrm{n}$ and $\mathrm{k}$ is in agreement with those reported for $\mathrm{NiO}$ single crystal $^{53}$ and films. ${ }^{28,54}$ The absorption coefficient $(\alpha)$ is presented in Fig. 4c, demonstrating that the deposited NiO film is highly transparent in the investigated spectral range. Considering a direct optical transition in $\mathrm{NiO}$ as per literature, ${ }^{16,35,46}$ i.e., $r=2$ in the Tauc relation $(\alpha h \nu)=A\left(h \nu-E_{\mathrm{g}}\right)^{1 / r}$, the variation of $(\alpha h \nu)^{2}$ versus $h \nu$ is plotted in Fig. $4 \mathrm{~d}$. The band gap $\left(E_{\mathrm{g}}\right)$ value is determined from the energy intercept by extrapolating the linear portion of the plot to $\alpha=0$. The $E_{\mathrm{g}}$ for ALD NiO film is extracted to be $3.75 \mathrm{eV}$, which is in good agreement with the values reported in the literature. $^{21,28,35,44-46}$

\section{ALD NiO as HTL in PSCs}

Having analyzed the structural and optical properties of the fabricated ALD films, the work then focusses on the implementation of NiO as HTL in PSCs. Fig. 5a presents a high-angle annular dark field (HAADF) STEM image of the cross-section of the complete planar PSC which consists of glass/ITO/pristine ALD NiO/ Perovskite/C60/BCP/Cu. In this stack, ITO serves as front electrode, ALD NiO as HTL, a "triple cation" $\mathrm{Cs}_{0.05}\left(\mathrm{MA}_{0.17} \mathrm{FA}_{0.83}\right) \mathrm{Pb}_{1.1^{-}}$ $\left(\mathrm{I}_{0.83} \mathrm{Br}_{0.17}\right)_{3}$ perovskite as photo-absorber layer, C60 and BCP together as electron transport layers and $\mathrm{Cu}$ as the back electrode. A high-resolution cross-sectional TEM image displaying the ITO/ $\mathrm{NiO} /$ perovskite interface is shown in Fig. 5b, where a $10 \mathrm{~nm}$ conformal NiO layer with excellent thickness homogeneity is clearly distinguishable from the adjacent ITO and perovskite layer. In addition, EDX elemental mappings are acquired at the PSC region depicted in Fig. $5 \mathrm{c}$ and the associated elements comprising of $\mathrm{Ni}$ (Fig. 5d) and I, Br, Pb, In, O and Cu are shown in Fig. S1(a)-(f) (ESI $\dagger)$.

Fig. 6a presents the $J-V$ scans of the PSCs with ALD NiO as HTL. It is observed that "key" to efficient solar cell performance is the post-annealing treatment of the ALD NiO films in air at $300{ }^{\circ} \mathrm{C}$ for $20 \mathrm{~min}$, prior to perovskite synthesis. A superior $17.07 \%$ PCE is demonstrated in the post-annealed NiO-based 
a)

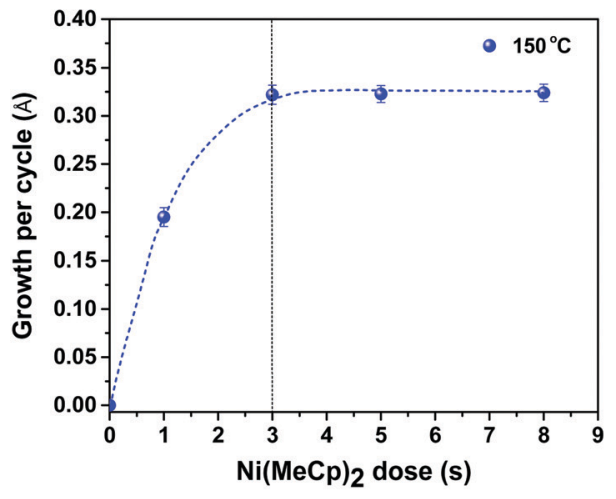

c)

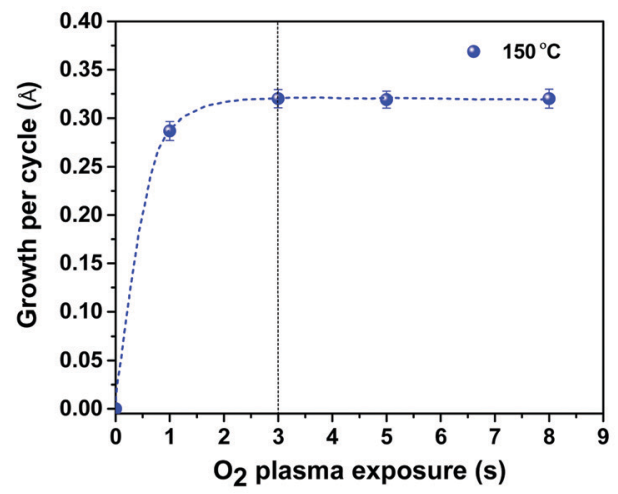

e)

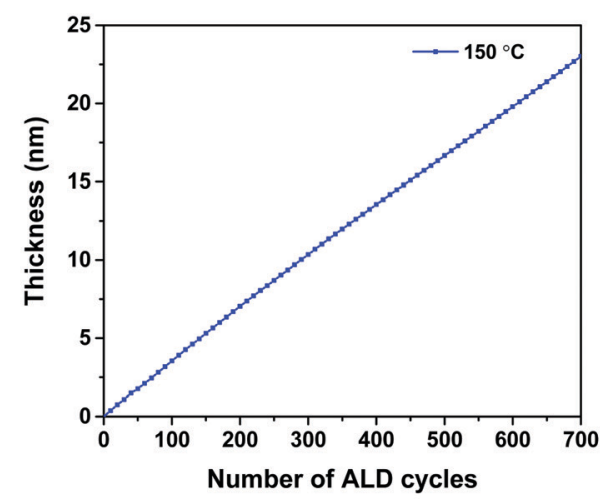

b)

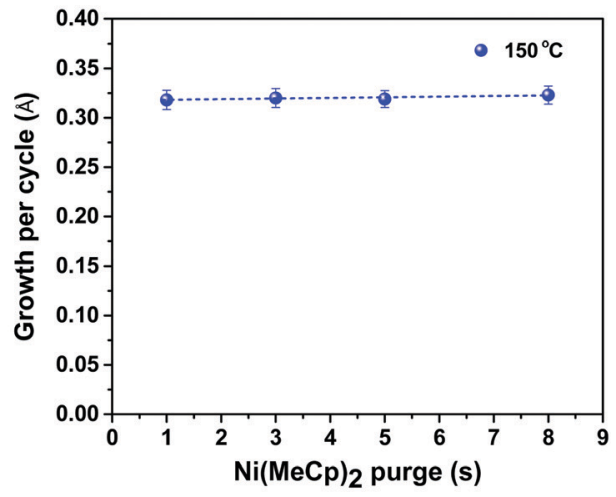

d)

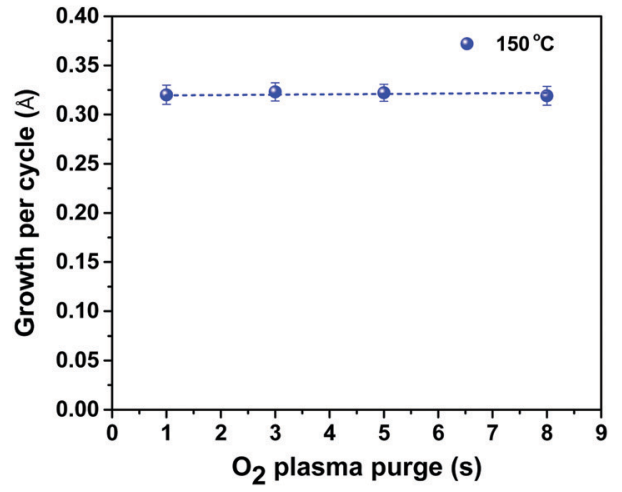

f)

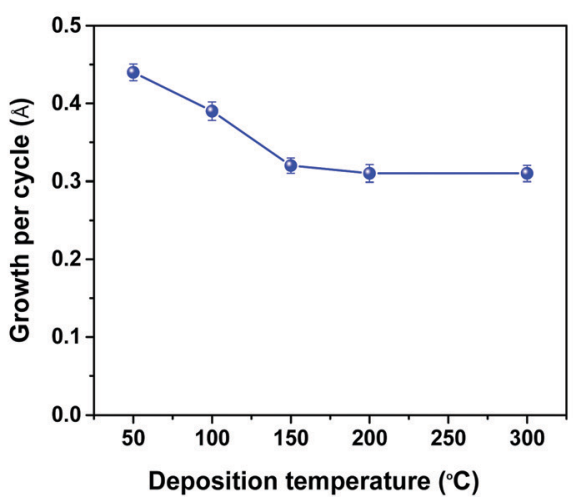

Fig. 2 Saturation curves: GPC as a function of (a) precursor $\mathrm{Ni}(\mathrm{MeCp})_{2}$ dosing, (b) $\mathrm{Ni}(\mathrm{MeCp})_{2}$ purge, (c) $\mathrm{O}_{2}$ plasma exposure, and (d) $\mathrm{O}_{2}$ plasma purge for deposition temperature of $150{ }^{\circ} \mathrm{C}$. The dashed lines serve as guide to the eye. (e) NiO film thickness as a function of number of ALD cycles. (f) GPC of NiO in terms of thickness for the investigated deposition temperatures.

device when compared to the $13.98 \%$ PCE derived from the one with pristine NiO. This enhancement arises from an increase in short-circuit current density $\left(J_{\mathrm{sc}}\right)$ and fill factor (FF), which indicates better light harvesting and hole extraction at the perovskite/post-annealed NiO interface. The increase in $J_{\mathrm{sc}}$ is also corroborated by the EQE spectra measured for both the investigated stacks (Fig. S2, ESI $\dagger$ ). The stabilized maximum power point (MPP) tracking results are shown in the inset of Fig. 6a and the PV parameters are summarized in Table 2. The performance of the PSCs has been reproduced for seven tested batches and the statistics of the PV parameters is demonstrated in Fig. S3 (ESI $\dagger)$. It is observed that the slope of $J-V$ curve at the $V_{\text {oc }}$ region becomes steeper in the annealed NiO devices. It is well-known that solar cells with a lower series resistance $\left(R_{\mathrm{s}}\right)$ exhibit $J-V$ curves with a steeper slope in the $V_{\text {oc }}$ region. For the cell with pristine $\mathrm{NiO}$, the value of the $R_{\mathrm{S}}$ is $12.3 \Omega \mathrm{cm}^{2}$ and for the post-annealed NiO device it is $7.8 \Omega \mathrm{cm}^{2}$. This difference in $R_{\mathrm{S}}$ could arise due to different charge extraction at the $\mathrm{NiO} /$ perovskite interface with respect to the post-annealing treatment of NiO. 


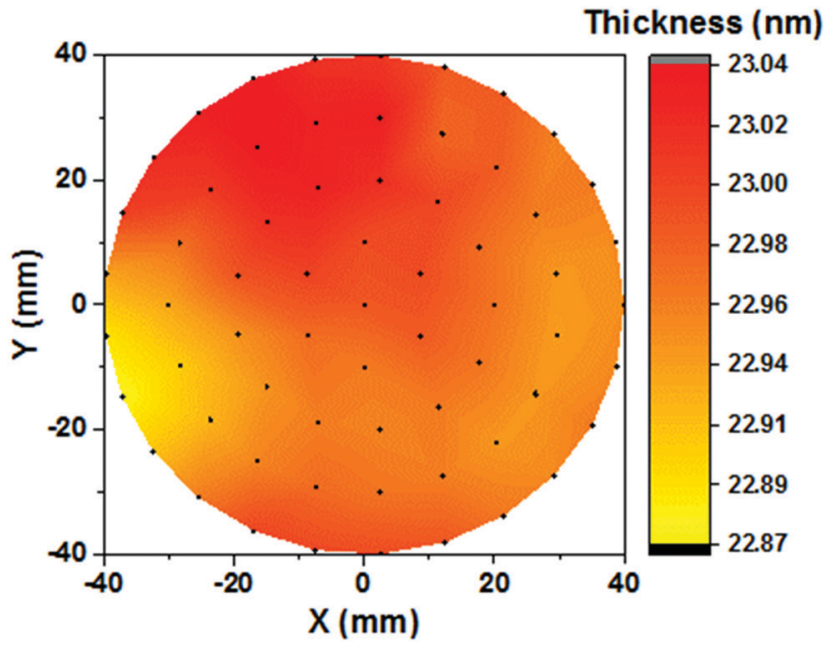

Fig. 3 Thickness uniformity of the ALD NiO film deposited at $150{ }^{\circ} \mathrm{C}$ on a 4 in $(100 \mathrm{~mm}) \mathrm{c}-\mathrm{Si}$ wafer, as-determined by room temperature SE mapping.

The difference in charge extraction can be analyzed by PL measurements. TRPL spectra of the perovskite films deposited on ITO/pristine $\mathrm{NiO}$ and ITO/post-annealed $\mathrm{NiO}$ substrates are presented in Fig. 6b. Considering that both perovskite layers have the same thickness (as confirmed from
TEM analysis), charge collection can be differentiated based on the perovskite/NiO interface status. A comparatively faster decay of the charge lifetime is observed for the perovskite deposited on the post-annealed NiO when compared to its counterpart grown atop pristine NiO. It is widely interpreted that a faster decay of the carrier lifetime is an indication of a more efficient charge extraction from the perovskite to the CTLs. ${ }^{55,56}$ The PL results strongly support the higher PCEs achieved in the post-annealed NiO devices. Alongside the improvement in PCE, it is remarkable to see that the devices with post-annealed ALD NiO experience a reduction in hysteresis (Fig. 6a). This points out that the hysteresis loss in PSCs can be mitigated by careful optimization of the interfaces. To date, the highest PCE of planar PSCs utilizing ALD $\mathrm{NiO}$ as HTL is $17.22 \% .^{23}$ The PCE obtained in this work is in line with the efficiencies that have been demonstrated for planar $\mathrm{p}-\mathrm{i}-\mathrm{n}$ PSCs based on undoped NiO HTLs, either processed by $\mathrm{ALD}^{21-23}$ or by other vacuum ${ }^{9,16,46}$ and solutionbased techniques. ${ }^{9,57-59}$

\section{ALD NiO and perovskite bulk analysis}

To understand why post-annealed NiO leads to better device performance, XRD is performed to investigate whether any bulk changes occur in $\mathrm{NiO}$ and $\mathrm{NiO} /$ perovskite samples with respect to the annealing treatment. As seen in Fig. 7a, no change in a)

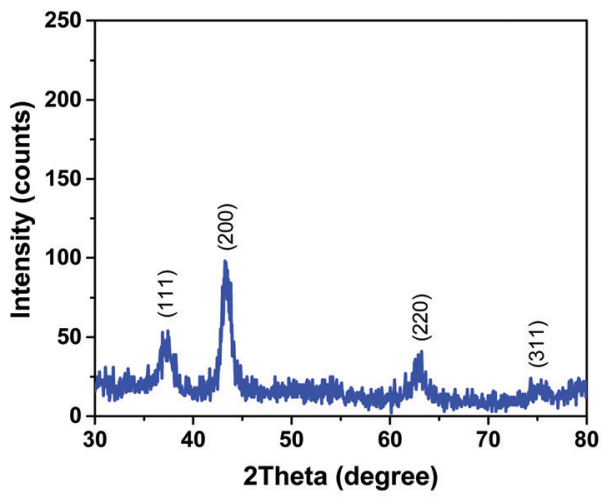

c)

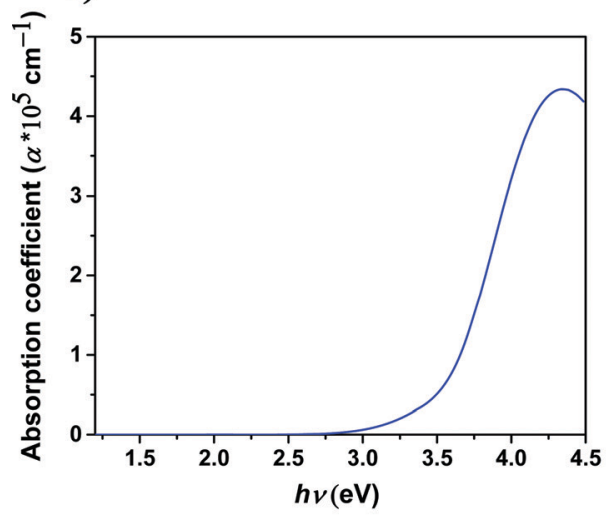

b)

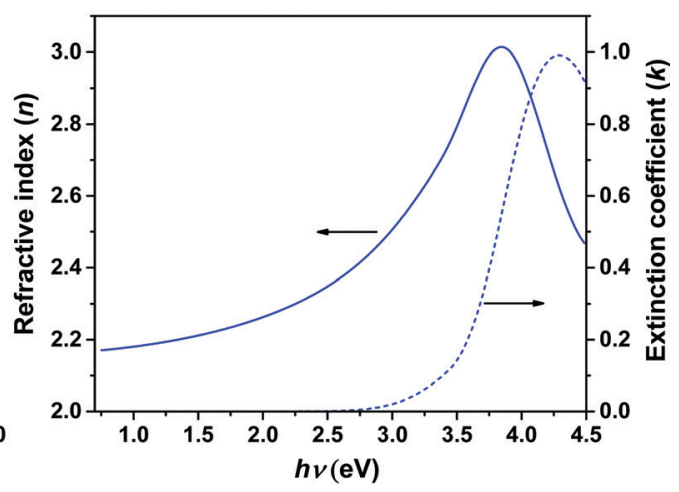

d)

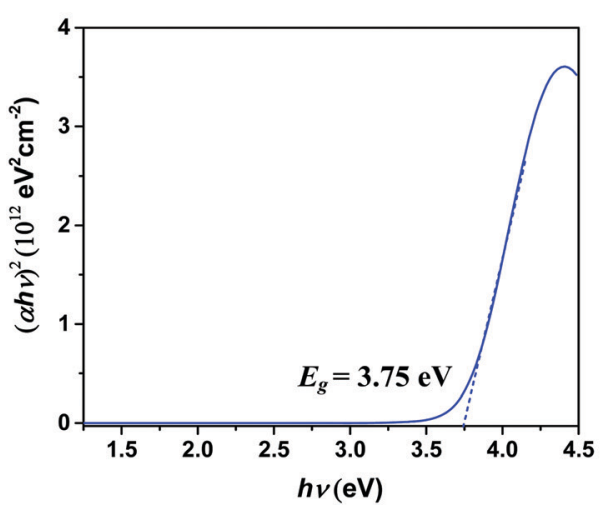

Fig. 4 (a) Gl-XRD spectrum of an as-deposited $10 \mathrm{~nm} \mathrm{ALD} \mathrm{NiO} \mathrm{film,} \mathrm{(b)} \mathrm{refractive} \mathrm{index} \mathrm{(} n$ ) and extinction coefficient ( $k$ ) spectra, (c) absorption coefficient $(\alpha)$ spectrum and (d) plot of $(\alpha h \nu)^{2}$ vs. $h \nu$ for a $23 \mathrm{~nm}$ ALD NiO film deposited on a Si substrate. 

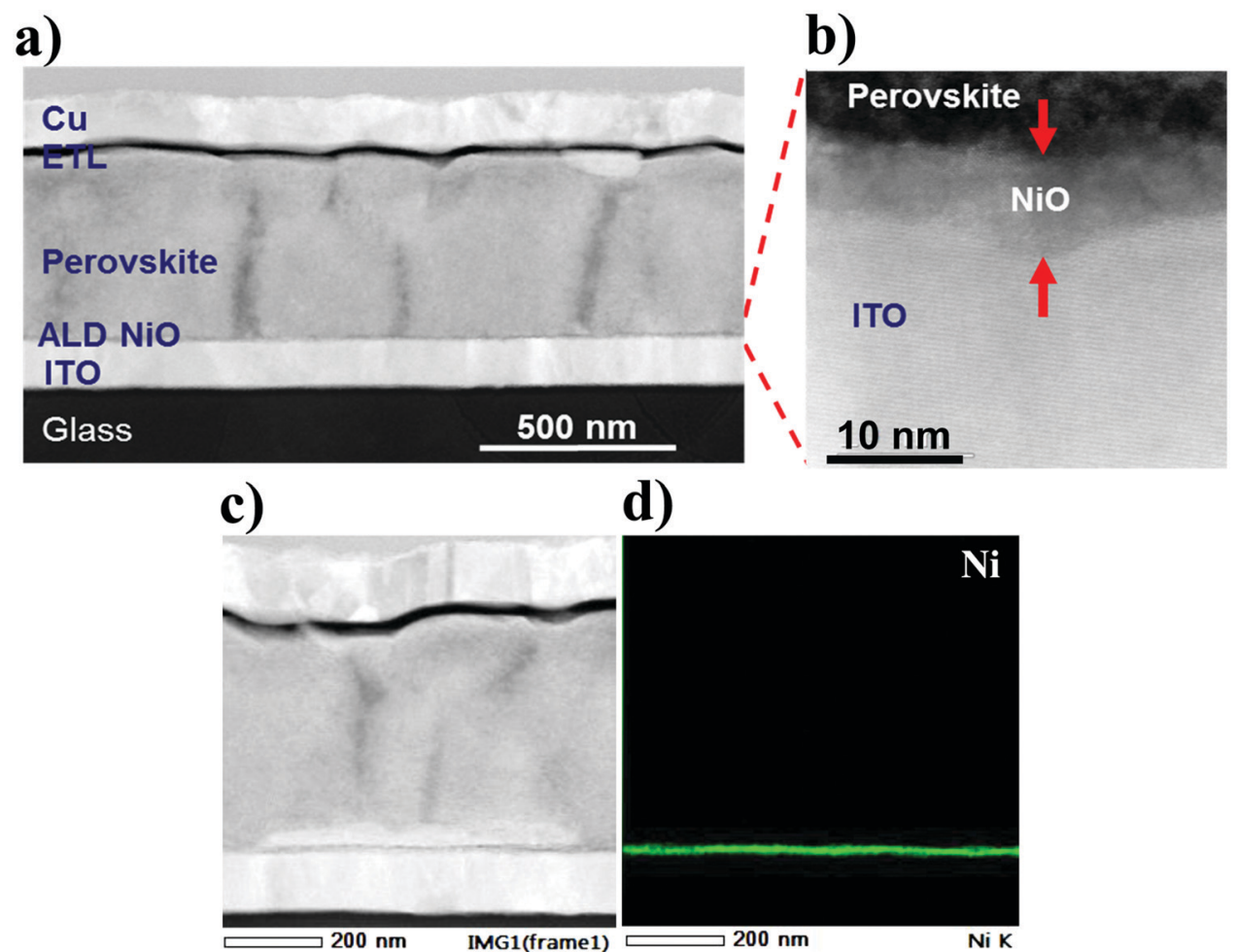

Fig. 5 Cross-sectional high angle annular dark field (HAADF) scanning TEM images (a) of the perovskite device stack, (b) of the perovskite/ALD NiO/ITO interface. (d) Elemental map of Ni acquired at the PSC region depicted in (c).

a)

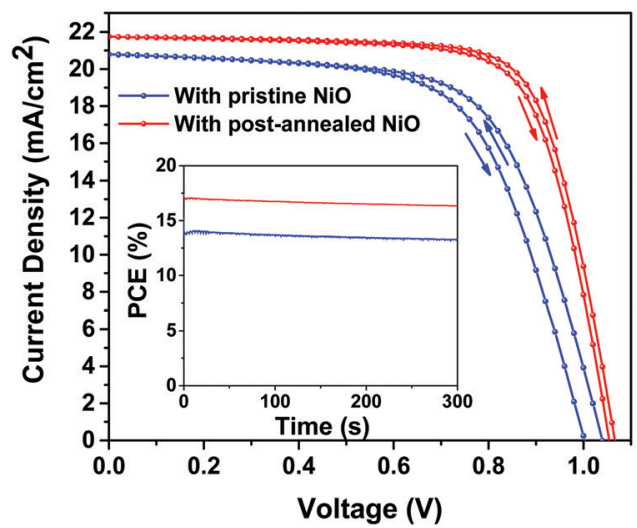

b)

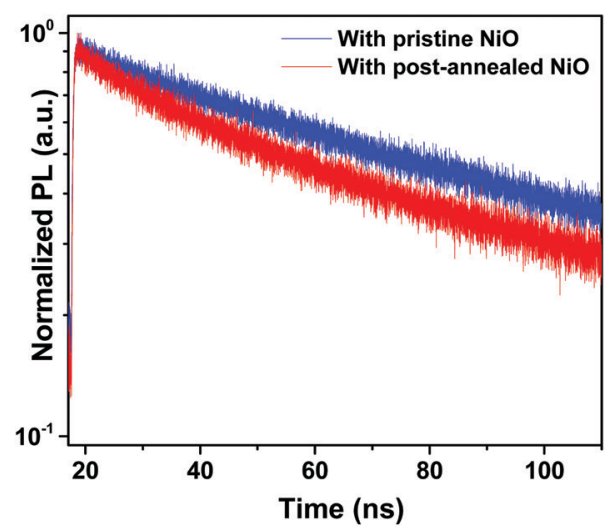

Fig. 6 (a) Forward and backward scanned J-V curves of the champion perovskite devices with pristine and post-annealed ALD NiO as HTLs. Inset shows MPP tracking for $5 \mathrm{~min}$ of both the devices. (b) TRPL spectra of glass/ITO/ALD NiO/perovskite samples comparing both the investigated NiO cases.

Table 2 PV parameters of the best PSCs employing pristine and postannealed ALD NiO as the HTL

\begin{tabular}{llllll}
\hline Condition & $\begin{array}{l}\text { Scan } \\
\text { direction }\end{array}$ & $\begin{array}{l}V_{\mathrm{oc}} \\
(\mathrm{V})\end{array}$ & $\begin{array}{l}J_{\mathrm{sc}} \\
\left(\mathrm{mA} \mathrm{cm} \mathrm{cm}^{-2}\right)\end{array}$ & $\begin{array}{l}\mathrm{FF} \\
(\%)\end{array}$ & $\begin{array}{l}\text { PCE } \\
(\%)\end{array}$ \\
\hline With pristine ALD NiO & $\begin{array}{l}\text { Backward } \\
\text { Forward }\end{array}$ & 1.04 & 20.80 & 64.67 & 13.98 \\
& & 20.80 & 63.36 & 13.18 \\
With post-annealed & Backward & 1.07 & 21.75 & 73.36 & 17.07 \\
ALD NiO & Forward & 1.05 & 21.75 & 72.42 & 16.54
\end{tabular}

crystallinity of ALD NiO is discerned by comparing the XRD spectrum of the films before and after annealing. In parallel, XRD analysis reveals no change in the crystallinity and morphology of the perovskite films grown on top of pristine and post-annealed NiO substrates (Fig. 7b). The results are corroborated by top-view SEM images of the perovskite films, showing no variation in the obtained morphology and a good crystallization quality on top of both the investigated $\mathrm{NiO}$ substrates (Fig. 7c and d). 
a)

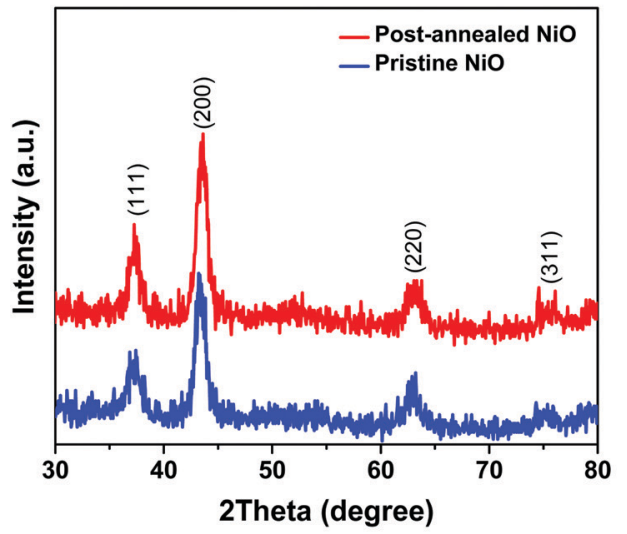

c)

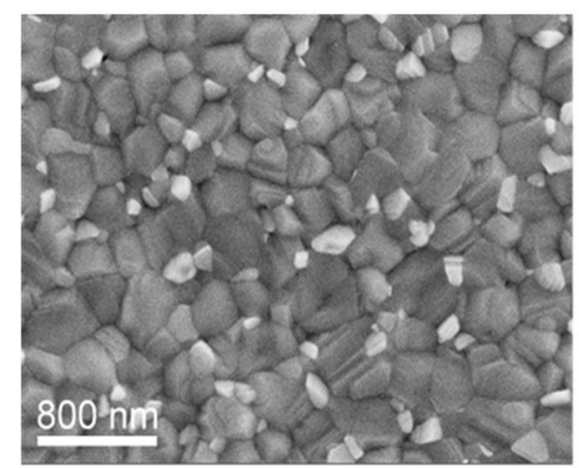

b)

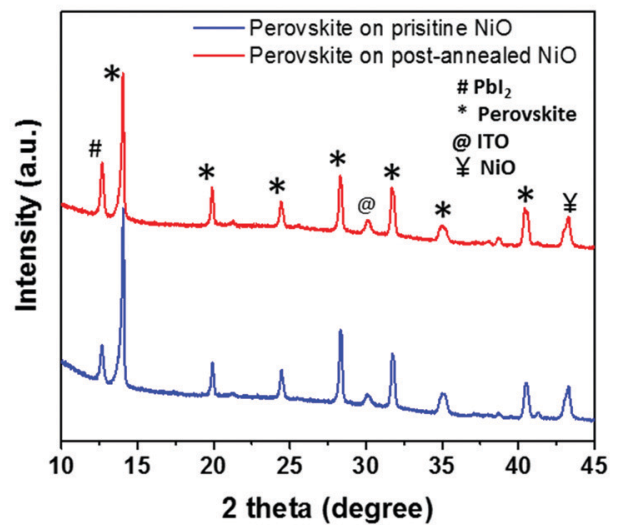

d)

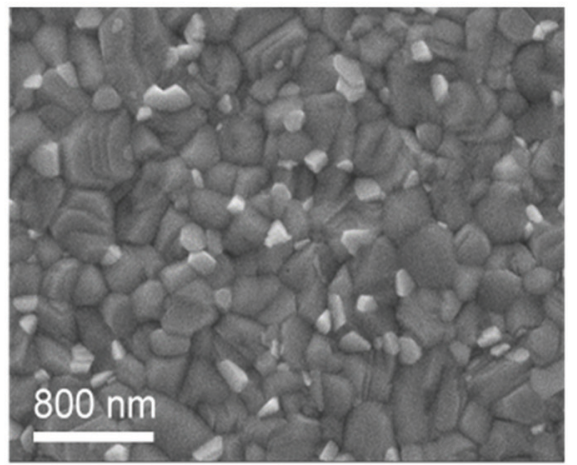

Fig. 7 (a) XRD spectra of the ALD NiO film before and after post-annealing at $300{ }^{\circ} \mathrm{C}$ in air for 20 min. (b) XRD spectra and top-view SEM images of the perovskite films deposited on top of (c) pristine and (d) post-annealed ALD NiO.

\section{ALD NiO/perovskite interface analysis}

Since the bulk properties of both $\mathrm{NiO}$ and perovskite films show no difference with respect to the annealing treatment, we then proceed with the analysis of the interface between the perovskite and the ALD NiO layer. First, AR-XPS measurements are performed on pristine NiO films with photoelectron take-off angles $(\theta)$ of $90^{\circ}$ and $15^{\circ}$. The results confirm that the concentration of hydroxyl species is higher at the surface of NiO (Fig. S4, ESI $\dagger$ ). Next, any subtle changes after post-annealing the NiO films are detected by performing XPS with $\theta$ of $15^{\circ}$. Fig. $8 \mathrm{a}$ and $\mathrm{b}$ presents the $\mathrm{Ni}$ a)

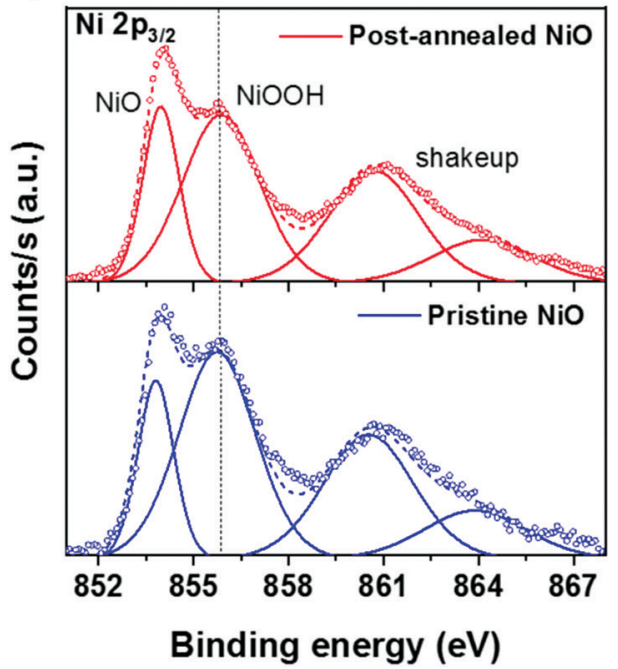

b)

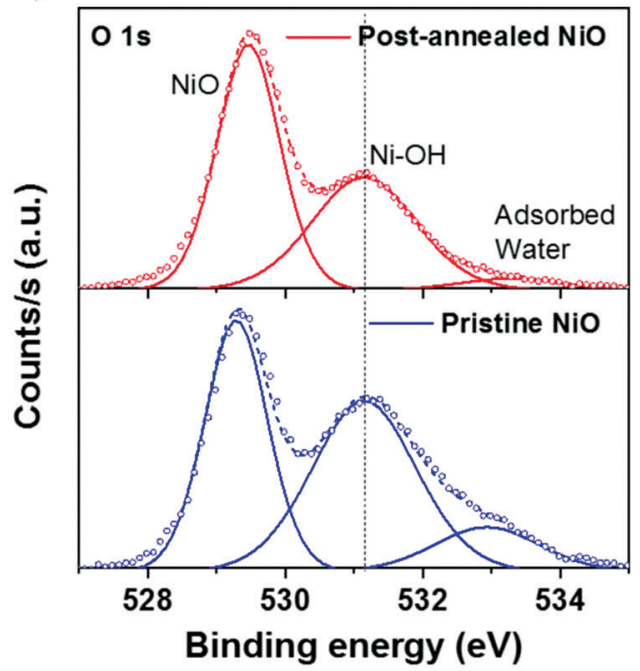

Fig. 8 XPS surface spectra of (a) $\mathrm{Ni} 2 \mathrm{p}_{3 / 2}$ and (b) O 1 s of the pristine (bottom frame) and post-annealed (top frame) ALD NiO films. Open circles, solid lines and dashed lines are measured data, peak fits and cumulative fits, respectively. 
$2 \mathrm{p}_{3 / 2}$ and $\mathrm{O}$ 1s XPS spectra with pristine (bottom frame) and post-annealed (top frame) ALD NiO films, respectively. We acknowledge that the exact assignment of the $\mathrm{Ni} 2 \mathrm{p}_{3 / 2}$ spectra to specific chemical environments is non-trivial, as it is wellknown that XPS analysis for the first row transition metals and their oxides and hydroxides is quite challenging due to the complexity of their $2 \mathrm{p}$ spectra, primarily arising from peak asymmetries, complex multiplet splitting, overlapping binding energies and shake-up phenomena. ${ }^{22,29,60}$ However, following the assignments reported in literature, ${ }^{22,29,61-64}$ the peak at $854 \mathrm{eV}$ (Fig. 8a) is ascribed to the oxidation state of $\mathrm{Ni}^{2+}$, which corresponds to $\mathrm{NiO}_{6}$ octahedral bonding in the cubic rock-salt $\mathrm{NiO}$ structure. The second peak at $855.8 \mathrm{eV}$ is attributed to $\mathrm{Ni}^{3+}$

a)

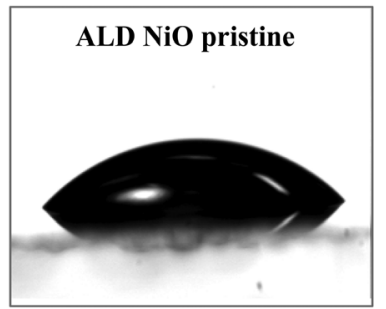

Fig. 9 Photographs of the contact angle measurements performed on the pristine and post-annealed ALD NiO samples. comprising of $\mathrm{NiOOH}$. The broad peaks located at $860 \mathrm{eV}$ and $864 \mathrm{eV}$ are related to shakeup processes (satellites) of NiO. Upon annealing the $\mathrm{NiO}$ films, the integrated area of $\mathrm{Ni}^{3+}$ peak decreases, indicating a decrease in the concentration of $\mathrm{NiOOH}$ species. The binding energy of the $\mathrm{O}$ 1s spectra (Fig. 8b) is mainly resolved into three oxygen states. ${ }^{22,29,61}$ The peak at $529.4 \mathrm{eV}$ is ascribed to $\mathrm{O}$ bonded as $\mathrm{Ni}-\mathrm{O}-\mathrm{Ni}$. The peaks at $531.1 \mathrm{eV}$ and $532.9 \mathrm{eV}$ are assigned to $\mathrm{O}$ bonded as $\mathrm{Ni}-\mathrm{OH}$ and adsorbed water, respectively. When comparing the $\mathrm{O} 1 \mathrm{~s}$ spectra of pristine and post-annealed films, it can be concluded that post-annealing leads to the elimination of hydroxyl groups and adsorbed water from the surface of ALD NiO. The $\mathrm{Ni}-\mathrm{OH} / \mathrm{NiO}$ ratio changes from 1.13 in the pristine to 0.76 in the annealed film.

In order to gain insights into whether the reduction of surface hydroxyl groups and adsorbed water has any influence on the perovskite/NiO interface quality, contact angle measurements are performed by drop-casting the perovskite precursor solution on top of the two investigated NiO surfaces. A reduction in the contact angle with respect to the post-annealing treatment is clearly evident when comparing the images in Fig. 9a and b, indicating better wetting of perovskite precursor solution on top of post-annealed $\mathrm{NiO}$ in comparison to the pristine film. The contact angle measurements confirm that post-annealing indeed changes the surface chemistry of ALD NiO (which is in agreement with our previous XPS analysis), leading to better interfacial properties with the adjacent perovskite layer. We expect that a)

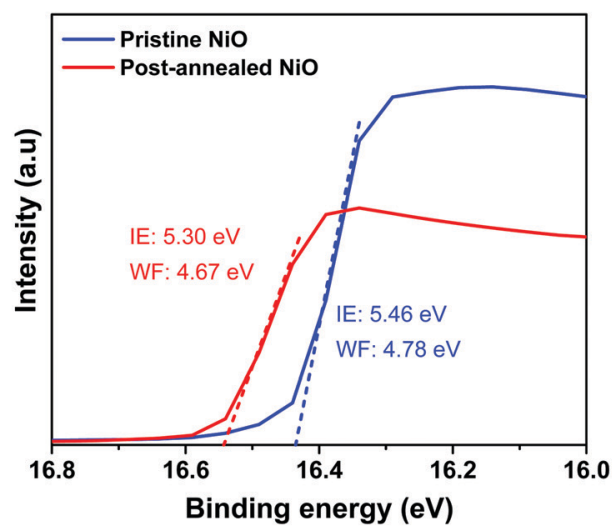

b)

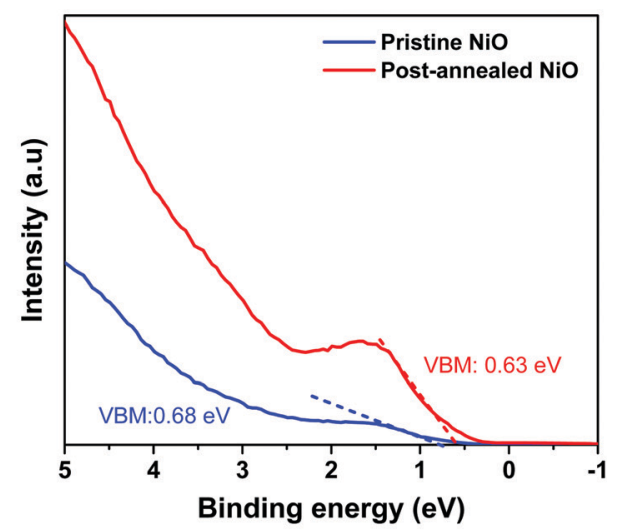

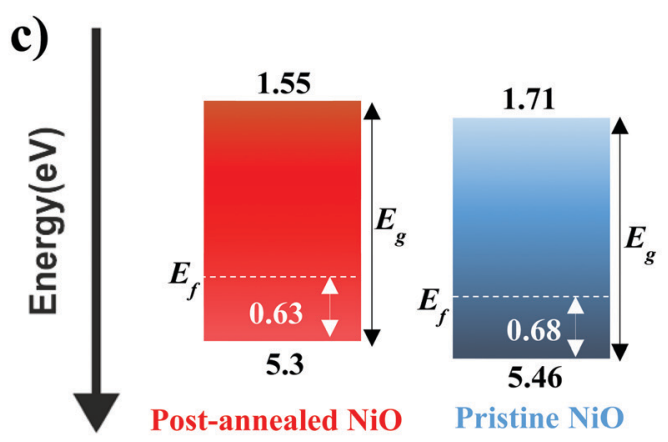

Fig. 10 (a and b) UPS spectra of $10 \mathrm{~nm}$ ALD NiO film (pristine and post-annealed). (c) Corresponding energy band diagram (in eV) with respect to vacuum level. 
better wetting of the perovskite precursor solution on top of post-annealed NiO could lead to improved performance in the fabricated solar cells.

Next, we analyze whether post-annealing affects also the energy band alignment of ALD NiO with the perovskite. UPS investigation allows to extract the valence band maximum (VBM) and ionization energy (IE) values for the pristine, postannealed NiO films and also for the employed triple-cation perovskite layer. More details on UPS data analysis can be found in the ESI $\dagger$ (Fig. S5). Fig. 10a and b shows the UPS spectra of the NiO films deposited on ITO substrates. A VBM of $0.68 \mathrm{eV}$ and an IE of $5.46 \mathrm{eV}$ are measured for the pristine ALD NiO sample. For the post-annealed NiO, a VBM of $0.63 \mathrm{eV}$ and an IE of $5.3 \mathrm{eV}$ are obtained. The perovskite film shows an IE of $6.05 \mathrm{eV}$ and VBM of $1.67 \mathrm{eV}$ (Fig. S6, ESI $\dagger$ ). The obtained values are in the range with those reported for mixed-cation perovskite ${ }^{65-67}$ and also for NiO deposited by different techniques. ${ }^{16,22,68,69}$ Based on UPS analysis, the energy band diagram of ALD NiO is sketched in Fig. 10c, with the band gap value of NiO being inferred by SE. When comparing the values of IE and VBM for the pristine and post-annealed $\mathrm{NiO}$, it can be observed that the differences are minimal. This indicates that the $V_{\mathrm{oc}}$ in the two investigated devices should hardly be influenced, which is in good agreement with our obtained $J-V$ results (Table 2 ).

A decrease in resistivity of the NiO films from $8.7 \times 10^{2} \Omega \mathrm{cm}$ to $1.7 \times 10^{2} \Omega \mathrm{cm}$ is observed after post-annealing, which can explain the decrease in $R_{\mathrm{S}}$ when comparing the corresponding PSCs. Resistivity is dependent on both carrier concentration and mobility of the films. Therefore, to assess whether there is a change in carrier concentration of the ALD NiO films after post-annealing, EIS is performed. Fig. 11 shows the MottSchottky plots of the two investigated NiO samples. The results reveal that post-annealing reduces the NiO carrier concentration in the films, from a pristine density of $(1.2 \pm 0.3) \times$ $10^{20} \mathrm{~cm}^{-3}$ to $(3.5 \pm 0.5) \times 10^{19} \mathrm{~cm}^{-3}$. This decrease in carrier concentration is accompanied by an increase in mobility of the

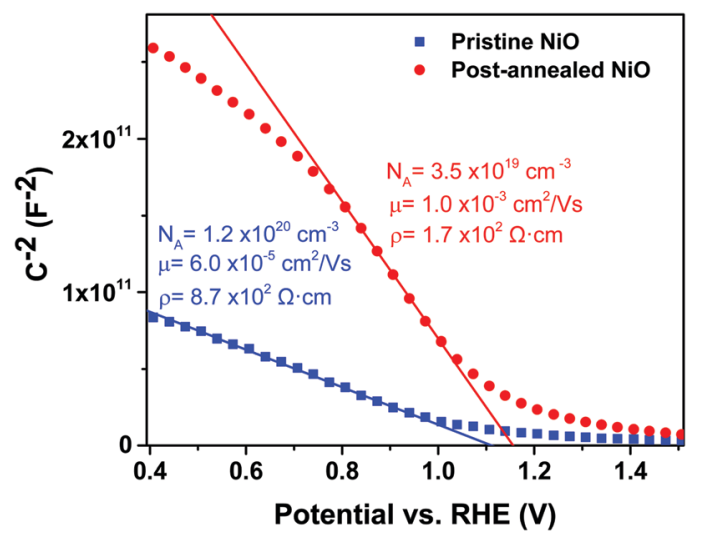

Fig. 11 Mott-Schottky plots of pristine and post-annealed ALD NiO samples, at $14 \mathrm{kHz}$ applied frequency. The legend shows the carrier concentration $\left(N_{A}\right)$ determined from the slope of the curve using the Mott-Schottky equation, resistivity $(\rho)$ from four point probe measurements, and hole mobility $(\mu)$ from $1 / \rho=q \mu N_{A}$, where $q$ is the elementary charge.
NiO films from $6.0 \times 10^{-5} \mathrm{~cm}^{2} \mathrm{~V}^{-1} \mathrm{~s}^{-1}$ to $1.0 \times 10^{-3} \mathrm{~cm}^{2} \mathrm{~V}^{-1} \mathrm{~s}^{-1}$, an effect that has been previously reported in the literature. ${ }^{70}$ The mobility and resistivity of our post-annealed NiO films are in good agreement with the values obtained for spatial-ALD NiO in the recent work of Zhao et al., where these films were utilized as HTL in PSCs. ${ }^{21}$ Our data support the evidence of higher $J_{\mathrm{sc}}$ and FF in the post-annealed ALD NiO-based devices, and thereby, higher PCEs in comparison to the cells with pristine NiO.

\section{Conclusions}

In summary, a plasma-assisted ALD process capable of producing high-quality thin films of $\mathrm{NiO}$ has been developed using $\mathrm{Ni}(\mathrm{MeCp})_{2}$ as precursor and $\mathrm{O}_{2}$ plasma as co-reactant within a table temperature range of $50-300{ }^{\circ} \mathrm{C}$. A linear growth behavior with a growth rate of $0.32 \AA$ per cycle is obtained at $150{ }^{\circ} \mathrm{C}$. The formation of polycrystalline, cubic NiO films with a $E_{\mathrm{g}}$ of $3.75 \mathrm{eV}$ is demonstrated, with excellent thickness uniformity on a 4 inch c-Si wafer. By implementing $10 \mathrm{~nm}$ conformal ALD NiO as HTL, efficient $\mathrm{p}-\mathrm{i}-\mathrm{n}$ PSCs are achieved based on triple cation perovskite. It is seen that post-annealing the ALD NiO layers delivers a superior PSC performance with $17.07 \%$ PCE when compared to the pristine NiO-based device with $13.98 \%$ PCE. In particular, the enhancement in PCE arises from an improved $J_{\mathrm{sc}}$ and FF in the post-annealed NiO devices. The higher $J_{\mathrm{sc}}$ and $\mathrm{FF}$ are the result of better hole extraction at the post-annealed HTL/perovskite interface, attributed to better wetting of the perovskite layer atop and increased conductivity and mobility of the NiO films after annealing. Meanwhile, both devices deliver similar $V_{\text {oc }}$ as confirmed by UPS analysis, showing negligible change in IE of the NiO films with respect to the annealing treatment. Our work elucidates that a careful design and optimization of the interface between perovskite and ALD NiO holds utmost importance, in addition to the superior bulk properties of the HTL itself, in order to effectively extract the holes and achieve efficient device performance. The choice of adopting ALD as a processing technique can aid in maximizing the surface coverage of the grown CTLs (especially on rough surfaces), thereby mitigating the shunting pathways as well as parasitic absorption losses in PSCs. In addition, suitability of ALD for large-area processing can contribute toward upscaling of perovskite PV technology.

\section{Conflicts of interest}

The authors declare no competing financial interest.

\section{Acknowledgements}

We acknowledge Dr Beatriz Barcones Campo for the FIB preparation of the TEM sample, Kseniia Korzun for the PL measurements, Yi Shu from Oxford Instruments for thickness uniformity measurements, Cristian van Helvoirt, Caspar van Bommel and Jeroen van Gerwen for the technical assistance. We are thankful to Dr Yinghuan Kuang, Valerio Di Palma and Dr Anna Todinova for the scientific discussions. Solliance is acknowledged for 
funding the TEM facility. We are grateful to the financial support from the Light Management in New Photovoltaic Materials (LMPV) research program of the Netherlands Organization for Scientific Research (NWO), from the Dutch Ministry of Economic Affairs, via The Top-consortia Knowledge and Innovation (TKI) Program "HighEfficiency Hybrid Tandem Solar Cells” (HIEFF) (TEZ0214010), "High-Efficiency Si Perovskite Tandem Solar Cells (HIPER)" (TEUE116193) and "ALD for hybrid perovskite solar cells (ALD4PSC)" (TKITOE1409105). M. Jošt and S. Albrecht acknowledge the funding by the German Federal Ministry of Education and Research (BMBF) via program "Materialforschung fuer die Energiewende" (grant no. 03SF0540).

\section{References}

1 NREL. Best Research-Cell Efficiencies http:/www.nrel.gov/ ncpv/images/efficiency_chart.jpg (accessed May 23, 2019).

2 A. Fakharuddin, L. Schmidt-Mende, G. Garcia-Belmonte, R. Jose and I. Mora-Sero, Adv. Energy Mater., 2017, 7, 1700623.

3 P. Schulz, D. Cahen and A. Kahn, Chem. Rev., 2019, 119, 3349-3417.

4 C.-G. Wu, C.-H. Chiang, Z.-L. Tseng, M. K. Nazeeruddin, A. Hagfeldt and M. Grätzel, Energy Environ. Sci., 2015, 8, 2725-2733.

5 T. Liu, K. Chen, Q. Hu, R. Zhu and Q. Gong, Adv. Energy Mater., 2016, 6, 1600457.

6 B. Chen, Y. Bai, Z. Yu, T. Li, X. Zheng, Q. Dong, L. Shen, M. Boccard, A. Gruverman, Z. Holman and J. Huang, Adv. Energy Mater., 2016, 6, 1601128.

7 K. A. Bush, A. F. Palmstrom, Z. J. Yu, M. Boccard, R. Cheacharoen, J. P. Mailoa, D. P. McMeekin, R. L. Z. Hoye, C. D. Bailie, T. Leijtens, I. M. Peters, M. C. Minichetti, N. Rolston, R. Prasanna, S. Sofia, D. Harwood, W. Ma, F. Moghadam, H. J. Snaith, T. Buonassisi, Z. C. Holman, S. F. Bent and M. D. McGehee, Nat. Energy, 2017, 2, 17009.

8 M. Jošt, T. Bertram, D. Koushik, J. A. Marquez, M. A. Verheijen, M. D. Heinemann, E. Köhnen, A. Al-Ashouri, S. Braunger, F. Lang, B. Rech, T. Unold, M. Creatore, I. Lauermann, C. A. Kaufmann, R. Schlatmann and S. Albrecht, ACS Energy Lett., 2019, 4, 583-590.

9 J. Chen and N.-G. Park, J. Phys. Chem. C, 2018, 122, 14039-14063.

10 Y. Wang, R. Wenisch, R. Schlatmann and I. Lauermann, Adv. Energy Mater., 2018, 8, 1801692.

11 F. Sahli, J. Werner, B. A. Kamino, M. Bräuninger, R. Monnard, B. Paviet-Salomon, L. Barraud, L. Ding, J. J. Diaz Leon, D. Sacchetto, G. Cattaneo, M. Despeisse, M. Boccard, S. Nicolay, Q. Jeangros, B. Niesen and C. Ballif, Nat. Mater., 2018, 17, 820-826.

12 Z. Jehl, M. Bouttemy, D. Lincot, J. F. Guillemoles, I. Gerard, A. Etcheberry, G. Voorwinden, M. Powalla and N. Naghavi, J. Appl. Phys., 2012, 111, 114509.

13 S. Sajid, A. M. Elseman, H. Huang, J. Ji, S. Dou, H. Jiang, X. Liu, D. Wei, P. Cui and M. Li, Nano Energy, 2018, 51, 408-424.
14 J. Burschka, N. Pellet, S.-J. Moon, R. Humphry-Baker, P. Gao, M. K. Nazeeruddin and M. Grätzel, Nature, 2013, 499, 316.

15 Z. Qiu, H. Gong, G. Zheng, S. Yuan, H. Zhang, X. Zhu, H. Zhou and B. Cao, J. Mater. Chem. C, 2017, 5, 7084-7094. 16 E. Aydin, J. Troughton, M. De Bastiani, E. Ugur, M. Sajjad, A. Alzahrani, M. Neophytou, U. Schwingenschlögl, F. Laquai, D. Baran and S. De Wolf, ACS Appl. Energy Mater., 2018, 1, 6227-6233.

17 J. Cui, F. Meng, H. Zhang, K. Cao, H. Yuan, Y. Cheng, F. Huang and M. Wang, ACS Appl. Mater. Interfaces, 2014, 6, 22862-22870.

18 W. Chen, Y. Wu, J. Liu, C. Qin, X. Yang, A. Islam, Y.-B. Cheng and L. Han, Energy Environ. Sci., 2015, 8, 629-640.

19 S. M. George, Chem. Rev., 2010, 110, 111-131.

20 S. E. P. H. C. M. Knoops, A. A. Bol and W. M. M. Kessels, Handbook of Crystal Growth, Elsevier, New York, 2nd edn, 2015, pp. 1101-1134.

21 B. Zhao, L. C. Lee, L. Yang, A. J. Pearson, H. Lu, X.-J. She, L. Cui, K. H. L. Zhang, R. L. Z. Hoye, A. Karani, P. Xu, A. Sadhanala, N. C. Greenham, R. H. Friend, J. L. MacManusDriscoll and D. Di, ACS Appl. Mater. Interfaces, 2018, 10, 41849-41854.

22 S. Seo, I. J. Park, M. Kim, S. Lee, C. Bae, H. S. Jung, N.-G. Park, J. Y. Kim and H. Shin, Nanoscale, 2016, 8, 11403-11412.

23 S. Seo, S. Jeong, C. Bae, N.-G. Park and H. Shin, Adv. Mater., 2018, 30, 1801010.

24 Y. Zhang, L. Du, X. Liu and Y. Ding, Appl. Surf. Sci., 2019, 481, 138-143.

25 C. Guan, Y. Wang, Y. Hu, J. Liu, K. H. Ho, W. Zhao, Z. Fan, Z. Shen, H. Zhang and J. Wang, J. Mater. Chem. A, 2015, 3, 23283-23288.

26 H. L. Lu, G. Scarel, C. Wiemer, M. Perego, S. Spiga, M. Fanciulli and G. Pavia, J. Electrochem. Soc., 2008, 155, H807-H811.

27 J. Bachmann, A. Zolotaryov, O. Albrecht, S. Goetze, A. Berger, D. Hesse, D. Novikov and K. Nielsch, Chem. Vap. Deposition, 2011, 17, 177-180.

28 H. L. Lu, G. Scarel, M. Alia, M. Fanciulli, S.-J. Ding and D. W. Zhang, Appl. Phys. Lett., 2008, 92, 222907.

29 K. L. Nardi, N. Yang, C. F. Dickens, A. L. Strickler and S. F. Bent, Adv. Energy Mater., 2015, 5, 1500412.

30 M.-H. Ko, B. Shong and J.-H. Hwang, Ceram. Int., 2018, 44, 16342-16351.

31 K. M. H. Young and T. W. Hamann, Chem. Commun., 2014, 50, 8727-8730.

32 E. Thimsen, A. B. F. Martinson, J. W. Elam and M. J. Pellin, J. Phys. Chem. C, 2012, 116, 16830-16840.

33 C.-C. Hsu, H.-W. Su, C.-H. Hou, J.-J. Shyue and F.-Y. Tsai, Nanotechnology, 2015, 26, 385201.

34 T. S. Yang, W. Cho, M. Kim, K.-S. An, T.-M. Chung, C. G. Kim and Y. Kim, J. Vac. Sci. Technol., A, 2005, 23, 1238-1243.

35 A. G. Hufnagel, A.-K. Henß, R. Hoffmann, O. E. O. Zeman, S. Häringer, D. Fattakhova-Rohlfing and T. Bein, Adv. Mater. Interfaces, 2018, 5, 1701531.

36 H. C. M. Knoops, T. Faraz, K. Arts and W. M. M. Kessels, J. Vac. Sci. Technol., A, 2019, 37, 030902. 
37 S.-H. Ji, W.-S. Jang, J.-W. Son and D.-H. Kim, Korean J. Chem. Eng., 2018, 35, 2474-2479.

38 S. J. Song, S. W. Lee, G. H. Kim, J. Y. Seok, K. J. Yoon, J. H. Yoon, C. S. Hwang, J. Gatineau and C. Ko, Chem. Mater., 2012, 24, 4675-4685.

39 K. E. K. Holden, C. L. Dezelah and J. F. Conley, ACS Appl. Mater. Interfaces, 2019, 11, 30437-30445.

40 M. Utriainen, M. Kröger-Laukkanen and L. Niinistö, Mater. Sci. Eng., B, 1998, 54, 98-103.

41 P. Antony Premkumar, M. Toeller, C. Adelmann, J. Meersschaut, A. Franquet, O. Richard, H. Tielens, B. Brijs, A. Moussa, T. Conard, H. Bender, M. Schaekers, J. A. Kittl, M. Jurczak and S. Van Elshocht, Chem. Vap. Deposition, 2012, 18, 61-69.

42 E. Lindahl, M. Ottosson and J.-O. Carlsson, Chem. Vap. Deposition, 2009, 15, 186-191.

43 S. B. S. Heil, E. Langereis, F. Roozeboom, M. C. M. van de Sanden and W. M. M. Kessels, J. Electrochem. Soc., 2006, 153, G956-G965.

44 D. Adler and J. Feinleib, Phys. Rev. B: Solid State, 1970, 2, 3112-3134.

45 H. Kamal, E. K. Elmaghraby, S. A. Ali and K. Abdel-Hady, J. Cryst. Grow., 2004, 262, 424-434.

46 T. Abzieher, S. Moghadamzadeh, F. Schackmar, H. Eggers, F. Sutterlüti, A. Farooq, D. Kojda, K. Habicht, R. Schmager, A. Mertens, R. Azmi, L. Klohr, J. A. Schwenzer, M. Hetterich, U. Lemmer, B. S. Richards, M. Powalla and U. W. Paetzold, Adv. Energy Mater., 2019, 9, 1802995.

47 E. Langereis, J. Keijmel, M. C. M. van de Sanden and W. M. M. Kessels, Appl. Phys. Lett., 2008, 92, 231904.

48 S. E. Potts, W. Keuning, E. Langereis, G. Dingemans, M. C. M. van de Sanden and W. M. M. Kessels, J. Electrochem. Soc., 2010, 157, P66-P74.

49 G. Dingemans, M. C. M. van de Sanden and W. M. M. Kessels, Electrochem. Solid-State Lett., 2010, 13, H76-H79.

50 G. Dingemans, C. A. A. van Helvoirt, D. Pierreux, W. Keuning and W. M. M. Kessels, J. Electrochem. Soc., 2012, 159, H277-H285.

51 S. Balasubramanyam, A. Sharma, V. Vandalon, H. C. M. Knoops, W. M. M. Kessels and A. A. Bol, J. Vac. Sci. Technol., A, 2017, 36, 01B103.

52 X. Yin, P. Chen, M. Que, Y. Xing, W. Que, C. Niu and J. Shao, ACS Nano, 2016, 10, 3630-3636.

53 R. J. Powell and W. E. Spicer, Phys. Rev. B: Solid State, 1970, 2, 2182-2193.
54 A. M. López-Beltrán and A. Mendoza-Galván, Thin Solid Films, 2006, 503, 40-44.

55 G. Xing, N. Mathews, S. Sun, S. S. Lim, Y. M. Lam, M. Grätzel, S. Mhaisalkar and T. C. Sum, Science, 2013, 342, 344.

56 Y. Lee, S. Lee, G. Seo, S. Paek, K. T. Cho, A. J. Huckaba, M. Calizzi, D.-w. Choi, J.-S. Park, D. Lee, H. J. Lee, A. M. Asiri and M. K. Nazeeruddin, Adv. Sci., 2018, 5, 1800130.

57 W. J. Scheideler, N. Rolston, O. Zhao, J. Zhang and R. H. Dauskardt, Adv. Energy Mater., 2019, 1803600.

58 T. Wang, D. Ding, H. Zheng, X. Wang, J. Wang, H. Liu and W. Shen, Sol. RRL, 2019, 1900045.

59 X. Zhao, J. Chen and N.-G. Park, Sol. RRL, 2019, 3, 1800339. 60 A. G. Marrani, V. Novelli, S. Sheehan, D. P. Dowling and D. Dini, ACS Appl. Mater. Interfaces, 2014, 6, 143-152.

61 J. W. Shim, C. Fuentes-Hernandez, A. Dindar, Y. Zhou, T. M. Khan and B. Kippelen, Org. Electron., 2013, 14, 2802-2808.

62 M. T. Greiner, M. G. Helander, Z.-B. Wang, W.-M. Tang and Z.-H. Lu, J. Phys. Chem. C, 2010, 114, 19777-19781.

63 A. P. Grosvenor, M. C. Biesinger, R. S. C. Smart and N. S. McIntyre, Surf. Sci., 2006, 600, 1771-1779.

64 L. Soriano, I. Preda, A. Gutiérrez, S. Palacín, M. Abbate and A. Vollmer, Phys. Rev. B: Condens. Matter Mater. Phys., 2007, 75, 233417.

65 H. Tan, A. Jain, O. Voznyy, X. Lan, F. P. García de Arquer, J. Z. Fan, R. Quintero-Bermudez, M. Yuan, B. Zhang, Y. Zhao, F. Fan, P. Li, L. N. Quan, Y. Zhao, Z.-H. Lu, Z. Yang, S. Hoogland and E. H. Sargent, Science, 2017, 355, 722.

66 Y. Kuang, V. Zardetto, R. van Gils, S. Karwal, D. Koushik, M. A. Verheijen, L. E. Black, C. Weijtens, S. Veenstra, R. Andriessen, W. M. M. Kessels and M. Creatore, ACS Appl. Mater. Interfaces, 2018, 10, 30367-30378.

67 J. P. Correa Baena, L. Steier, W. Tress, M. Saliba, S. Neutzner, T. Matsui, F. Giordano, T. J. Jacobsson, A. R. Srimath Kandada, S. M. Zakeeruddin, A. Petrozza, A. Abate, M. K. Nazeeruddin, M. Grätzel and A. Hagfeldt, Energy Environ. Sci., 2015, 8, 2928-2934.

68 S. Yue, K. Liu, R. Xu, M. Li, M. Azam, K. Ren, J. Liu, Y. Sun, Z. Wang, D. Cao, X. Yan, S. Qu, Y. Lei and Z. Wang, Energy Environ. Sci., 2017, 10, 2570-2578.

69 J. Kim, H. J. Park, C. P. Grigoropoulos, D. Lee and J. Jang, Nanoscale, 2016, 8, 17608-17615.

70 S. Han and A. J. Flewitt, Sci. Rep., 2017, 7, 5766. 